\title{
Emotional Reflexivity and the Guiding Principle of Objectivity in an Inter-Disciplinary, Multi- Method, Longitudinal Research Project
}

\author{
by John Stephen McKenzie \\ The Open University in Scotland
}

Sociological Research Online, 22 (1), 8

$<$ http://www.socresonline.org.uk/22/1/8.html>

DOI: $10.5153 /$ sro.4210

Received: 25 Jun 2016 I Accepted: 16 Jan 2017 I Published: 28 Feb 2017

\begin{abstract}
This paper demonstrates how emotional reflexivity can help researchers aspire to the benchmark of objectivity. It will be argued that emotional exchanges during interviews with research participants can enhance understanding based on the author's research experiences in an inter-disciplinary, multi-method, longitudinal study of low-energy, social housing in Aberdeen, Scotland. It will then be demonstrated that emotional reflexivity allowed the researcher to identify how his feelings of empathy with the household occupants, who had had a negative experience, developed and how he began to share their frustrations and disappointments with the Council. This allowed him to locate himself within the research field, and help him understand how this influenced his representation of this group. This consequently allowed him to moderate his focus on the negative experiences of some occupants and produce a more comprehensive account of the full range of the householders' perspectives. In conclusion, it will be argued that emotional reflexivity can help researchers maintain the guiding principle of objectivity whilst locating the researcher within the field and therefore can provide an effective means of negotiating the pitfalls of the reflexive turn.
\end{abstract}

Keywords: Emotional Reflexivity, Emotions, Field Position, Guiding Principle of Objectivity, Reflexive Turn

\section{Introduction}

1.1 In this paper, I aim to demonstrate how emotional reflexivity can help researchers aspire to the guiding principle of objectivity and negotiate the pitfalls of the reflexive turn based on my research experiences in an inter-disciplinary, multi-method, longitudinal study of low-energy social housing in Aberdeen, Scotland. The first step in this paper will be to provide a literature review around the themes of objectivity, emotions, field position and the reflexive turn before outlining the study undertaken. It will then be argued that the author's first-hand exposure to the emotional stories told by some participants during the three rounds of in-depth interviews enhanced his understanding of the household occupants. Following this, it will be demonstrated how emotional reflexivity allowed the author to understand the developing empathy he felt with these participants and how he began to share their frustrations and disappointment with the response of some council workers, and the effect this had on his interpretation of research findings. Further reflection on the impact the emotional exchanges had on him also allowed him to locate himself within the research field and to understand the influence this had on his representation of the research field. This then allowed him to temper his focus on the negative experiences of some of the household occupants and produce a more comprehensive report on a fuller range of occupants' perspectives. This, it will be argued, allowed the author to enhance the degree of objectivity achieved in this project and provided a useful means of negotiating the reflexive turn. Throughout, it will also be demonstrated that emotions and emotional reflexivity are multi-layered and have implications for research participants, research teams and for the knowledge that emerges from the research. 
Emotions have always been central to sociological analyses and occupied an absent presence in classical sociology (Shilling 2003). However, historically, social scientists widely assumed that, by focusing on the production of knowledge as the sole aim of sociological enquiry, researchers could minimise bias (Hammersley 2000). However, Becker (1967) and Gouldner (1973) created debate when they argued that the value-free sociology advocated by Weber is an unobtainable goal and the use of the concept of bias in evaluating research has been problematized for assuming a positivist ontology (Hammersley and Gomm 1999). According to Cunliffe (2003) social scientists have contested the conventional notion of social reality, knowledge and the validity of social inquiry to provide an absolute objective view of the world. Christians (2011: 74-75) further points out that there has now been an emergence of 'a new model of research ethics in which human action and conceptions of good are interactive' resulting in a field of qualitative research which 'advances social justice and is grounded in hope'. Thus, the kind of objectivity required for a value-free approach is both unlikely and, even if it could be achieved, overrated (Lumsden 2012). Social researchers are socialized beings and, whilst objectivity is a useful benchmark for guiding research (Bourdieu and Wacquant 2007), it is never something that we can fully achieve for our values, attitudes and beliefs will impact upon the research we carry out and our findings. Therefore, I agree with Becker (1967) when he points out that sociological analysis is always from a particular perspective or, as many feminists such as Hartsock (1983) say, from an epistemological standpoint. Finch (1984) points out that this is particular pertinent in studies of women and researchers need to be wary as to how female participants' perspectives are represented. Whilst this feminist perspective is not central to the argument presented in this paper, it has to be acknowledged that the researcher comes from a particular perspective before, during and after the research has taken place (Homfray 2008) and that the resultant data emerges from the contextual relationship between the researcher and the researched (Broom et al. 2009). Therefore, the researcher needs to ensure that the standpoint adopted provides an inclusive account and does not misrepresent the views of research participants (Finch 1984; Broom et al. 2009; Delamont 2016). Ward (2016: ix) warns that researchers need to be aware of how our identities impact on our ability to 'elicit data that is valid, truthful and useful...'. In line with the reflexive turn, researchers must therefore reflect on their experiences and reveal the influence field position has on their representations.

\section{The reflexive turn and the guiding principle of objectivity}

1.3 Reflexivity, however, poses a problem for researchers. We have to reflect upon our position within the research field and our methodology but, at the same time, we also have to avoid: perpetually deconstructing our arguments; narcissistic navel-gazing by placing our position ahead of the research participants; and, in pointing to the shortcomings of our methodologies, undermining the validity of our research (Finlay 2002; Petray 2012). Instead, we must reflect upon our research fields and findings in such a way that it adds legitimacy to our authorial voices (Brewer 2000). The effect of the researcher in the field can be positive and reflexivity 'does not require us to give up the guiding principle of objectivity' (Hammersley and Gomm 1997: para 4.12. To quote Bourdieu at length:

\footnotetext{
To adopt the point of view of reflexivity is not to renounce the objectivity but, on the contrary, to give it its full generality by questioning the privilege of the knowing subject, arbitrarily freed, as purely noetic, from the work of objectivation. It is to work to account for the empirical "subject" in the very terms of the objectivity constructed by the scientific "subject"- in particular by situating him or her at a determinate place in social space - and, thereby, to acquire awareness and (possible) mastery of all the constraints that may impinge on the scientific subject through the ties that bind him to the empirical objects, those interests, pulsions, presuppositions, with which he must break in order fully to constitute himself as such (Bourdieu and Wacquant 2007: p. 214).
}

1.4 The guiding principle of objectivity in this study therefore relates to adopting a field position that allows the researcher to account for the widest array of participants' voices. At the same time, and in line with the demands of the reflexive turn, it also relates to locating the researcher within the field and revealing how this has influenced the interpretation of the research data and the representation of it.

1.5 However, tackling the reflexive turn is no simple matter. In this paper, I will demonstrate how emotional reflexivity can provide a useful means of negotiating the pitfalls of the reflexive turn (Petray 2012) and should therefore be seen 'as a resource rather than a methodological problem' (Blackman 2007: p. 701). Emotional reflexivity has been used in a variety of ways (for an example see Goleman (1996)). Here, emotional reflexivity refers to both reflecting on emotions and the effects emotions have on reflecting, which will also be influenced by the temporal and spatial distance from the research field. Burkitt (2012: 459) argues that emotion should be understood: 
context of social interactions and relationships in which they arise. Emotion is not just something that we reflect on in a disengaged way, it is central to the way people in social relations relate to one another: it is woven in the fabric of the interactions we are engaged in and it is therefore also central to the way we relate to ourselves as well as to others.

\section{Emotional Reflexivity and the Reflexive Turn}

The founding figures of sociology, Durkheim, Marx and Weber, paid little explicit attention to emotions.

This is perhaps because emotions were assumed to pose a threat to the objectivity claims of the rational scientist (Hubbard et al. 2001; Gray 2008; Kleinman 2002). This kind of attitude still persists in the wider professional field today to some extent, at times, alienating qualitative researchers from their quantitative colleagues (Kleinman 2002). That is, quantitative methods are typically seen as more objective than qualitative Tewksbury 2009). Kleinman and Copp (2009: p. 66) say:

\footnotetext{
As members of the larger discipline, fieldworkers share a culture dominated by the ideology of professionalism, or, more specifically the ideology of science. According to that ideology, emotions are suspect. They contaminate research by impeding objectivity, hence they should be removed.
}

1.7 This can create a dilemma for the social researcher debating whether or not to report on emotional dimensions of their work (Romocea 2016) and has led to some researchers leaving the emotional aspects of their research unreported (Blackman 2007; Dickson-Swift et al. 2009). However, Kleinman (2002) and Cantó-Milá (2016) points out that emotions became a more legitimate focus of study for sociologists in the 1970s and 80s. Drawing on the dramaturgical approach of Goffman, Hochschild (1985) blazed the trail for the growth of the sociology of emotions in her study of airhostesses in Delta Airlines and the sociology of emotions is now a wellestablished field of study, which cannot be fully reviewed here. Key concepts pertinent to this paper will be explained

1.8 Cantó-Milá (2016:1.2) argues that emotions should be understood as feelings 'individual have and sometimes share and as invisible threads that bind us together in endless webs of interrelations' and that 'they are socially constructed through discourse as well as through repeated practices that cultivate certain emotions over others and certain ways of experiencing them over an array of options'. That is, our emotions are guided by what Hochschild (1985) called feeling rules, which refer to standards relating to what is due and owing in the currency of emotions in different social setting and encounters. Flam and Kleres (2016:1.3) explain that feeling rules 'tell members of any given society when to feel which emotion(s), and also with what intensity and duration'. Hochschild (1985) also makes an important distinction when she further points that we employ emotional labour when following feeling rules during paid employment and emotional work when we follow feeling rules outside of it. Both have costs for the individual but Hochschild (1985) argues that emotional labour can take a greater toll on the psychological welfare of the individual who may be coerced into displaying emotions that do not correspond with their internal feelings. For Barbalet (2002:1) 'emotion simply indicates what might be called an experience of involvement... that a person cares about something registers in their physical and dispositional being. It is the experience that is the emotion...' Seebach and Nùnez-Mosteo (2016) further argue that sharing these experiences creates links between those who feel the emotion and those for, or because of whom, they feel it. These concepts, amongst others, have provided useful frameworks for researchers to reflect upon their emotional experiences whilst conducting social research as part of the reflexive turn and there is now a wealth of literature surrounding this issue.

1.9 Bellas (1999: p.104) states that 'Despite the emphasis on emotional detachment and neutrality, researchers can become deeply involved in their subjects' lives, particularly when there is sustained contact between researchers and subjects'. Therefore, whilst emotions may not be absent from other types of research (Seal 2012), it is the researcher using ethnographic techniques who may be more emotionally involved with the research field (Petray 2012), because they spend more time interacting with research participants in an attempt to capture their world view. Qualitative researchers, however, may feel reluctant to report these feelings because they feel vulnerable to criticisms of the broader professional field (Kleinman 2002; Blackman 2007; Seal 2012).

1.10 Indeed, Burkitt (2012) argues that emotions have been perceived as a barrier to clear reflexive thought and Holmes (2010) points out that theories of reflexivity have tended to ignore emotions. However, Romocea (2016) argues that emotions do not compromise the scientific standard of research but rather adds a new dimension to doing research. Feminist methodology has now 'made the role of the researcher's emotions explicit in the research process' (Hubbard et al. 2001: 124) and those who have tackled the dual dangers of the reflexive 
turn and talking about emotions have demonstrated that feelings have significance when conducting research. For example, Seal (2012) discusses the implications her feelings of ambivalence towards women accused of murder had in her archival research of representations of them. However, it is ethnographic researchers who have explored the impact of emotions on research in the greatest depth. They have discovered that emotions, such as sadness and euphoria, can enhance ethnographic knowledge (Hubbard et al. 2001; Holland 2007; Dickson-Swift et al. 2009; Petray 2012). Hubbard et al. (2001: 120) argue "emotionally-sensed knowledge' is an indispensable part of the research process'. It has also been argued that revelatory moments when conducting ethnography can be stimulated by deeply emotional experiences (Trigger et al. 2012; Henry 2012). Thus, it has been recognized that knowing and feeling cannot be separated and emotions therefore have epistemological significance which should not be ignored (Hubbard et al. 2001; Holland 2007; Gray 2008). Indeed, Flam and Kleres (2016:1.4) argue that scholarly discourse can be understood as 'a specific interpretation of reality with implicit or explicit emotion' and I agree with Kleinman (2002:382) when she argues that ignoring emotions in research could be considered 'a form of neglect'.

1.11 Many researchers have now demonstrated the benefits of reflecting on the emotional aspects of research. In trying to capture the worlds of the participants, ethnographic researchers must develop an empathy with their subjects if they wish to produce credible ethnographic knowledge (Petray 2012) and it has been recognised that developing empathy involves emotional labour on the part of the researcher (Hubbard et al. 2001). Gray (2008: 936) says 'the nature of the relationship between the researcher and the object of study has important affective dimensions with implications for research practice'. Blackman (2007) explicitly explores this issue in Hidden Ethnography when he crosses 'emotional borders' and discusses the significance of emotional relationships between the researcher and the researched in his qualitative studies of young people's lives. Goodrum and Keys (2007) and Dickson-Swift et al. (2009) further discuss the emotional labour carried out by qualitative researchers when researching sensitive topics, arguing that such research is an embodied experience and can be damaging for both the researcher and participants. Blackman (2007:705) further points out sensitive research can intrude on areas that are 'private, stressful and sacred'. Researchers therefore need to employ strategies to promote self-care and the care of the participants (Dickson-Swift et al. 2009; Goodrum and Keys 2007; Hubbard et al. 2001).

1.12 Furthermore, the emotional impact of the research relationship does not end when the researcher leaves the field. Hammersley and Atkinson (1995) contend that researchers rarely leave the field unaffected by the research experience and must therefore continue to reflect upon the impact the complex identities and relationships within the research field have on our representations of it to the wider community (Coffey 1999; 2002). That is, we may require a spatial and temporal distance from the research field in order to be effectively reflexive (Coffey 1999). Hubbard et al. (2001: p.121) say 'The emotions of the respondent and also those of the researcher are likely to influence and inform our understandings of the topic under investigation'. Delamont (2016) further argues that qualitative researchers need to be more reflexive in their account of leaving the research field as exiting the research field can have an impact on our understanding of the research field and will impact upon our representations of it.

1.13 Therefore, emotional experiences in the research field can lead to the researcher developing a particular perspective (Petray 2012). This is an issue that has been explored by Lumsden f012) in "You are what you research" where she evaluates how her position within the research field impacted her research of 'boy racer' culture in Aberdeen, Scotland. She describes how she unintentionally 'took sides' with the boy racers in her research and reflects on how this affected her representation of the subculture. That is, she felt a responsibility to give voice to the underdog viewpoint in public debates. Indeed, critical ethnographers often adopt an overtly critical and political approach towards the research field as they aim to expose inequalities in an effort to affect social change (O'Reilly 2009). However, I agree with Lumsden when she concludes, 'As part of the reflexive turn, researchers should be open to an examination of their values on (amongst other things) the research process, their representations of the researched and the dissemination of research findings' (2012: p. 7-8).

\section{The Study}

2.1 This paper is based on a longitudinal, multi-method, inter-disciplinary study of low-energy, social housing in Aberdeen, Scotland, which took place between January 2012 and June 2013. The houses, based in three different sites, used a variety of sustainable technologies including: air source heat pumps; solar hot water panels; photovoltaics; mechanical ventilation heat recovery; triple glazing; grey water recycling (for the flats) and rainwater harvesting (for houses). The research was commissioned by Aberdeen City Council (ACC) in response to the mixed experiences of occupants. That is, whilst some occupants seemed happy in their new homes, ACC faced serious complaints about breakdowns in technology and high electric bills. This research was funded to try 
The study involved a survey, the collection of technical data, workshops, three rounds of in-depth, qualitative interviews and a research diary. It involved researchers from different disciplines including the social sciences (both qualitative and quantitative), science and engineering. This paper is primarily based on the qualitative, in-depth interviews that the author carried out and the research diary he kept, because, whilst emotions may not be absent from other methodological approaches, it is those researchers who spend more time with participants who may become more emotionally involved with the research field (Petray 2012; Brewer 2000).

2.3 The sample comprised fourteen households of different types and is illustrative rather than representative (Mason 2002). Participants across all adult age groups and both genders were represented in the sample, which included families with and without children and individuals living alone. Depending on the wishes of the research participants, some interviews were conducted with two adult residents of the household and, in others with just one. Participants were identified, in part, as self-selectors through volunteering at the initial public workshops as well as through 'snowball' sampling via word of mouth recommendations by ACC. However, not all households participated in all the follow up interviews with one dropping out at the second round and a further four at the final round. This was due to the difficulties in organising a convenient time for the interview to take place and to participant fatigue (Clark 2008).

2.4 The next step will be to describe the emotional stories told during the household interviews and the impact this had on the researcher and his consequent representations of the research field. The names of participants have been removed to protect their identities in line with ethical standards of good practice.

\section{Emotional exchanges, field position and representation}

3.1 After experiencing a number of complaints from householders in the new low-energy housing regarding technical problems and high electric bills, ACC funded research to investigate the householder experience. From the outset, it seemed that some residents viewed the situation as a battle between ACC and the household occupants. When I became involved with the study the principal investigators reported that emotions were 'running high' amongst many of the household occupants across the three sites. Whilst many of occupants professed that they 'loved' their new homes at the initial workshops, others displayed anxiety and anger surrounding the technical problems and allegedly high energy costs.

3.2 The survey findings reflected these issues and pointed to differing feelings towards the new homes. Some reported that they were very happy: 'Generally speaking I am extremely satisfied with this flat' (Survey, July 2012). However, others highlighted frustrations around technical problems and costs. For example, when asked the open question if they thought the technology was worthwhile, one respondent replied:

If I had the chance I would move out of this house due to all the problems and high rent that goes with it. No one at the council seems to care that we go six days sometimes without a shower or hot water. If a solution is not found shortly I will be demanding a move out of here (Survey, July 2012).

However, it was not until the household interviews took place that the full level of emotion became apparent to me.

\section{Household Interviews and emotionally-sensed knowledge}

3.3 The level of emotion circulating amongst the interviewee took me by surprise as it was not something that I had fully anticipated, as indicated by my research diary entry after one of the first interviews:

This interview seemed to go very well. This occupant had a lot of problems, particularly initially. I could feel that she was becoming rather upset when talking about her problems and it struck me that this is not something I had banked on. This made me feel a little awkward and I thought it may be worth discussing with the research team in advance of the next round of interviews (Research diary, 8/8/12).

3.4 In other studies, the willingness of participants to vent emotions openly in interviews has been put down to the intimacy of the research setting and to the trusting relationship developed between the researcher and the participants (Bailey 2008) However, in this study, it may be that participants volunteered for the research as they wanted an opportunity to vent their anger. From the moment I contacted occupants to organise interviews, some were keen to express their feelings about their new homes. When calling an occupant to organise an interview, 
he stated that 'I would be sorry to ask them about their home'. He felt that 'it was a disgrace how they had been treated by the Council' (Research diary, 8/8/12). On arriving at the homes of participants, some started to complain when they answered the door:

The occupants in this household said that they hoped that I was ready for their complaints. From the minute of entering the house, both occupants complained that this house was not what they had been promised. They felt that they had been misled and were paying for the privilege of putting up with problems like not having heating or a flushing toilet (Research diary 11/8/12).

These interactions were important and demonstrated that interviews begin at the point you make contact with participants (Bailey 2008) and highlights the importance of recording these exchanges in a research diary. That is, the diary can allow the researcher to capture the emotional impact of the interview encounter that may not be immediately evident when reading the interview transcript alone (Broom et al. 2009). This points to the primary importance of the experiential component of emotion (Barbalet 2002).

3.6 When conducting interviews some of the questions received an emotional response. For example, one couple saw no advantage to moving to their new home:

Interviewer: So are there advantages to having moved here?

Interviewee 1: No. I would rather deal with the stairs ${ }^{[1]}$ than the trouble that we've had. I mean, even outside the cost of the electricity bills, the cost of being left with no shower for ten days, em... it's just, it's a good idea but they've done it wrong.

Interviewee 2: If it had worked, if we'd come in, I know there's going to be teething problems, but if everything had worked as it's supposed to, it would be ideal. Like if we didn't have to wait ten days for a shower because that's our only method of washing apart from a tiny sink. D'you know what I mean? We've had to then go down to family and friends or whatever to get showers, you know. It's just ridiculous that somebody can leave us ten days without any proper washing facilities. (Interview 1, 11/8/12).

3.7 After this interview concluded, the couple informed me that other occupants on this site had already put in for a council transfer due to high energy costs and technical problems. They then went on to say that they were 'trapped' in their new home because there was so little social housing available with the disabled access they required (Research diary, 13/8/12). This conveyed to me how desperate they must feel in their current housing situation and I could sense feelings of empathy for these residents growing stronger and I felt motivated to help them as much as I could. That is, the sharing of emotions created a link between the interviewer and the interviewees (Cantó-Milá 2016; Seebach and Nùnez-Mosteo 2016).

3.8 Some participants became visibly upset during the interview. Whilst interviewing an elderly woman she said that she could feel herself 'becoming upset' as she recounted the technical problems she had with her toilet, her heating and hot water when she moved in. She explained that the lack of heating and hot water caused her arthritic pain to worsen and how embarrassed she felt having to ask to use her neighbour's toilet when hers was not working (Interview 1, 8/8/12). I could see her trying to control her emotions, holding back tears and wringing her hands, and it became clear that participants had to employ emotional work during the interview process (Hochschild 1985). It also pointed to the possible influence that emotional experiences can have on participant's accounts of their experiences and indicates that participants also engage in emotional reflexivity during the research process. Thus, emotions influence memories whilst at the same time remembering influences our current emotional states.

3.9 The above interview had a particularly strong impact on me - I could feel myself becoming emotional as I imagined how my mother (of a similar age to the participant) would feel in such a situation. Not wanting the emotional exchange to escalate, as I could sense that the participant wanted to control her emotions for fear of embarrassment and I wanted to maintain a professional demeanour, I listened to her story quietly before moving on. On reflection, it struck me that there is an emotional cost for both participants and researchers when conducting research in which participants reflect on emotionally charged, negative experience. Participants engage in emotion work, whereby they try to control their negative emotions, whilst researchers engage in emotional labour by controlling their emotional responses. In not responding to the research participant in the way I would a friend, also instilled feelings of guilt on my part. This fuelled an increasing responsibility to represent these participants' perspectives to the research team and ACC. It also occurred to me that negative emotions may have a more powerful impact on researchers when listening to participants' accounts of their experiences than positive ones. 
3.10 The second round of interviews revealed the continuing emotional impact the technical problems and high costs had on the occupants in the new homes. One occupant claimed that the financial stress caused by high rents and energy bills took its toll on her marriage:

Interviewer: So what kind of impact have all these problems had on your life then? Interviewee: My marriage breakdown.

Interviewer: Ok.

Interviewee: Because it's either pay your rent or worry about your energy prices that you're having to pay. With all the faults and everything that's gone on in the house, it leads to arguments and worries, and my marriage broke down (Interview 2, 5/12/12).

3.11 When discussing this issue, I could see that the interviewee was trying to control her emotions by avoiding eye contact and maintaining a steady voice. In this instance it seemed that she was using emotion work to follow feeling rules she felt framed the encounter. This made me feel a little awkward as I wanted to show sympathy without escalating her emotional state.

3.12 Another occupant became upset as she explained that moving to her new home had completely changed her lifestyle, and that of her children, in a detrimental way:

Interviewer: How has moving here impacted upon your lifestyle?

Interviewee: Em, I just think over in my old house I did not have much worries, you know, I could put on my electric I did not ever think oh I cannot put on the kettle or I cannot put on the TV. But here I'm constantly worried, and I just feel it was the worst decision in my life to take a house like this. Do you know what I mean? (Interview 2, 3/12/12).

3.13 During this part of the interview, the interviewee became upset and I had to switch the recorder off to allow her to take a breather. She went on to explain that, due to the high rents and energy bills, she could not afford to live in her new home on the benefits she received and her teenage daughter had, therefore, to give up a promising career in football to get a paid job so that they could afford the bills (Research diary, 3/12/12). Again, I could recognise the reciprocation between the emotion work and costs to the participant and the emotional labour of the researcher following standardised protocols to deal with upset research participants. That is, I had to follow guidelines drawn up by the research team in line with professional ethics and, in doing so, my response felt unsatisfactory as I would have liked to have shown my sympathies more overtly. It occurred to me that my lack of emotional response to participants' stories could also appear unsympathetic to the research participants. This may have contributed to research fatigue and participants withdrawing from the study or appearing less enthusiastic to participate in follow-up interviews. This is demonstrated in notes taken in my research diary during the last round of interviews:

\begin{abstract}
When I arrived for interview the participants were not at home. I waited and the female householder drew up in the car. She said that she forgot about me coming today and she was busy but to come in 'anyway'. Whilst I chatted to her, she carried on putting shopping away and repeated that she and her family were 'fed up with the whole thing and she could not be bothered talking about it anymore'. I therefore decided to forgo the interview and informed her that her views would be put forward to the council in the final report. This stood in contrast to the earlier enthusiasm this household displayed when they initially volunteered to take part in the research (Research diary, 15/1/13).
\end{abstract}

3.14 It may also go some way to explain why a number of participants reported feeling 'fed up' and appeared less motivated to participate in the second and third interviews, with some participants dropping out. This points to an important consideration when conduction longitudinal research of negative experiences in that the ongoing cost of emotional reflexivity and emotional work of participants, coupled with the muted emotional response of the professional researcher, may discourage participants completing the research project. This suggest that, whilst sharing emotional experiences can link people together, a failure to display emotions can result in a disconnection between them. It also highlights the importance of providing care for both research participants and researchers when dealing with emotional subject matter (Dickson-Swift et al. 2009; Goodrum and Keys 2007; Hubbard et al. 2001).

3.15 These qualitative interviews allowed me to empathise with the emotional impact moving into these homes had on occupants. I could easily identify with the technical and financial problems and imagine the kind of impact that they would have on elderly relatives and single-parent families within my own family. I also shared some of their frustrations and disappointments. I believe, therefore, that I developed a fuller understanding of these research participants. This demonstrates how 'emotionally-sensed knowledge' can enhance ethnographic understanding (Hubbard et al. 2001). I will now go onto demonstrate how reflecting on these emotional aspects of the research also allowed me to understand how my feelings of empathy with these occupants developed and how this then effected my representation of the research field. 


\title{
Emotions, field position and representation
}

3.16 From the beginning of the report writing stage, it seemed clear that I was more motivated to present a fuller account of the occupants' negative experiences. For example, on reading the first report for ACC, I noted that the technical problems and high costs faced by occupants had not been fully documented. The project leaders explained that this was because the Council already had a record and knowledge of the complaints. However, I argued that some occupants felt that their complaints had not been fully heeded:

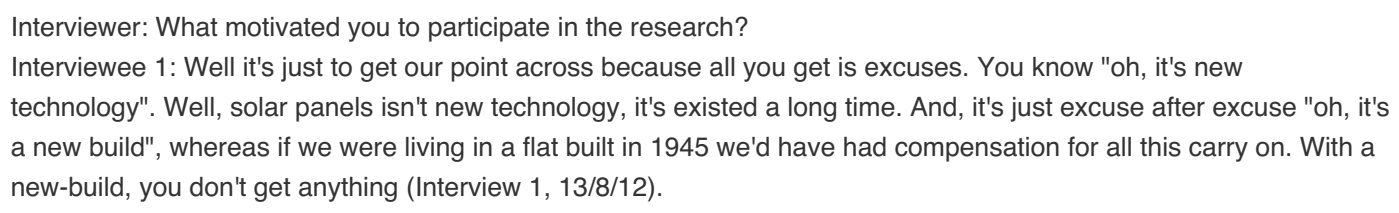

3.17 I, therefore, argued that we had a responsibility to represent the occupants' views and give voice to a less powerful group as repayment for their time and cooperation in the research process (Lumsden 2012). The team agreed to some extent and added more ethnographic detail surrounding technical problems and high costs to the report with a fuller summary of problems added as an appendix. Similarly, in the second report, I felt that the impact the technical problems and high costs had on the lives of the occupants needed to be documented with examples from the second round of interviews. Whilst some ethnographic detail was then added to the report, I still felt that more emotive examples could have been used. However, I felt that I could not further my case against the wishes of the senior researchers. This is illustrated in a note in my research diary:

\begin{abstract}
After reading the draft of the second report for ACC I felt disappointed that more details of the residents' negative experiences had not been included. I emailed the principal investigators who replied that we needed to focus on ways to improve the experience. I still felt guilty that I had not been able to represent these householders in the way I would have liked but had to be satisfied that I had tried to get their voice heard and had succeeded to some extent (Research diary 10/3/13).
\end{abstract}

3.18 It also struck me that the project leaders seemed focused on evidence of learning and adaptation at the expense of problems. For example, I was somewhat surprised to read discussions of local 'experts' and 'champions' when I felt that the evidence continued to point to continuing technical problems and a lack of knowledge and understanding of the technologies. On discussing this with one of my colleagues, he explained that he wanted to produce a report that the Council and householders would find useful rather than reminding them of problems. He also pointed out that his disciplinary baggage as an educational researcher probably shaped his reading of the data. This highlights the importance of researchers' biographies and one of the advantages of reflexivity as a collective process (Pilnick 2013). Indeed, further reflection on my part highlighted that I needed to be careful not to be so influenced by the negative experiences that it excluded the perspectives of residents who reported a more positive experience. This further implies that negative emotions may be more influential than positive and may require more close scrutiny in our reflections.

3.19 Thus, emotional reflexivity allowed me to reveal how my field position influenced my interpretation of the data. That is, the emotional stories told during the interview resulted in my developing a greater empathy with those research participants who had had a negative experience than others in the research team. I am not, therefore, suggesting my colleagues did not sympathise with the occupants, but I am arguing that my first hand exposure to their stories led to a fuller understanding of the emotional impact moving to their new home had and provided me with a fuller understanding of their situation. In this case listening to the emotional stories of the occupants deepened my understanding of this particular group within the research field and enhanced my ethnographic knowledge (Hubbard et al. 2001). My colleagues, who tendered for the research project and who had spent more time with the council representatives, may have had a greater understanding of what was required by the funders and a fuller understanding of their viewpoint. We, therefore, occupied different positions within the research field which impacted upon how we wished to present our research findings. Whilst it is not an issue that will be fully explored here, this points to the importance of power, politics and the construction of knowledge in funded research and a potential role for emotional reflexivity in exploring these dynamics. What I hope to demonstrate here is how emotional reflexivity enhanced the degree of objectivity attained in this project.

\section{Emotional reflexivity and the guiding principle of objectivity}

3.20 On reflection, it became clear that many of my additions to the report were about the negative experience of some participants. When looking back through the data again, there was clear evidence that some occupants were happy in their new home. For example, one occupant commented: 'I would recommend these technological systems to be installed in all social housing. It would save people on low incomes an awful lot of 
money, and make a big impact in reducing carbon emissions' (Survey, July 2012). Similarly, there were those respondents who reported liking their new homes:

Interviewee: Yes, the house is great. Much more room than my last place and the people are nice - the neighbours ' $n$ that, ken. The wifey from the coonsil as well, she's been really good, getting things fixed and showin' us how to work the heatin' (Interview 2, 5/12/12).

3.21 Furthermore, whilst some occupants had very expensive energy bills, which were difficult to account for, others perceived their bills to be greater than they actually were. For example, four occupants, who claimed that their energy bills were much higher than their previous home, proved to be mistaken when costs were explored in greater detail in the second round of interviews. These perceptions, I feel, were affected by the high levels of anxiety across the sites. One occupant said that she was 'worried' about her forthcoming bill, even though she had yet to receive one. Many occupants also spoke about residents getting to get together to discuss bills as they came in:

Interviewer: Do you discuss your bills with your neighbours?

Interviewee: Yes, it's just like, as soon as the post hits the mat we're all out into the park to discuss how much we've been ripped off this time (Interview 1, 10/8/12).

3.22 It seemed to me that the negative emotions surrounding energy bills and technical problems amplified perceptions of cost amongst occupants. Similarly, when asked about the information and guidance given and what they had learned about the technologies many of the occupants offered negative replies:

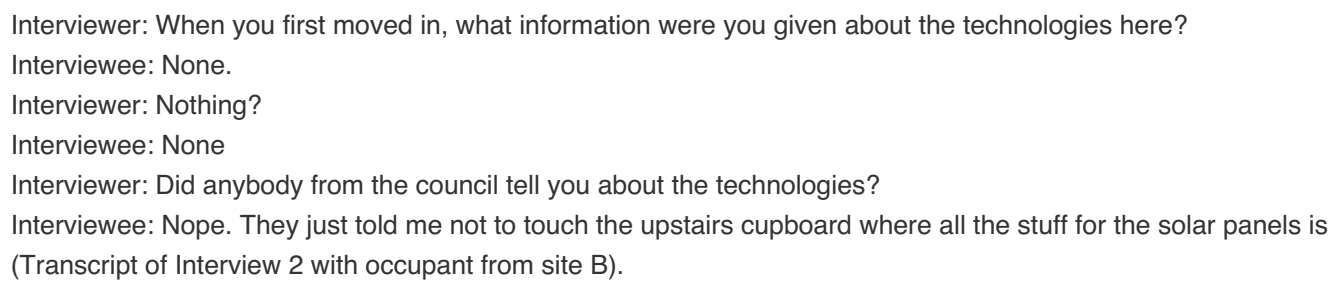

3.23 Another typical response from occupants claimed that the only thing they had learned about the technology was that 'it does not work'. However, when probed further, it became apparent that occupants had been given some information and guidance in the form of manuals and demonstrations and many had learned a lot about the technology in their homes. For example, there was some evidence of occupants fixing problems with their neighbours' heating and hot water. It occurred to me that the stress and anxiety caused by the technical problems and the failure to achieve quick repairs had overshadowed the learning experience. The emotional experiences coloured the resident's accounts and highlights the importance of considering the effect negative experiences can have on research participants and their accounts. I can now also recognise that in sharing these anxieties with occupants during the interviews my perceptions could have also been influenced. This, in turn, could have then led me to emphasise these negative experiences at the expense of the positive. By focusing on these problems, I could therefore hinder the objectives of others in the research team They therefore to remind me that one of the aims of the research project was to try to get past the focus on technical problems and high costs and, instead, to identify ways to improve information and guidance, maximize the learning experience and to encourage cost efficient practices. It is also important, however, to keep in mind that these reminders of the Council and research team objectives changed my position within the research field and, in turn, my interpretation and dissemination of the research data. It must also be recognised that one advantage of group research projects is that colleagues can stimulate reflexivity and encourage a more balanced analysis (Pilnick 2013).

\section{Conclusion}

4.1 Historically, whilst the links between emotions and knowledge have been long established, emotions have not been an explicit focus for sociological researchers nor in their discussions of methodology because they were perceived to pose a threat to the objectivity claims of the social researcher (Hubbard et al. 2001; Kleinman 2002). However, whilst objectivity should remain as a guiding principle in social research, it has rightly been recognised as overrated (Lumsden 2012) and unobtainable (Gouldner 1973) and emotions have been an increasingly important research area since the 1970s and 1980's (Kleinman 2002). Feminists demonstrated the importance of reflecting on emotions and the research process as part of the wider reflexive turn in the social sciences (Hubbard et al. 2001) and there is now a plethora of literature surrounding emotions and research. Qualitative researchers are particularly concerned with emotions and research but there are dangers to both reflecting on emotions and the reflexive turn more broadly. Emotions can still be seen as un-scientific by the 
wider professional community and reflexivity can undermine the validity of the research. However, those researchers who have tackled the dual dangers of discussing emotions and the reflexive turn have demonstrated the importance of 'emotionally-sensed knowledge' in developing an ethnographic understanding of the research field (Hubbard et al. 2001) and the advantages of reflecting on emotions (Blackman 2007; Gray 2008; Burkitt 2012). Drawing on my research experience in an inter-disciplinary, multi-method, longitudinal study of lowenergy, social housing in Aberdeen commissioned by Aberdeen City Council (ACC), this paper demonstrates that emotional reflexivity can help locate the researcher within the field and reveal the relationship between field position and data interpretation and representation, whilst enhancing the degree of objectivity achieved in the research. In doing so, emotional reflexivity can help the researcher negotiate the dual dangers of discussing emotions in social research and the reflexive turn.

I have argued that, due to my first-hand exposure to the stories of participants during the qualitative interviews, the emotionally-sensed knowledge enhanced my understanding of their situation in comparison to others in the research team. During these interviews, I developed an empathy with those occupants who reported perpetual technical problems and allegedly high energy costs and shared some of their frustrations and disappointments. This, in turn, led to my desire to give voice to this less powerful group in the reports produced for ACC. However, reflecting on the effect negative experiences had on the accounts of the research participants and the consequent effect the emotional stories of participants had on me, as well as on my reflections and on my contribution to reports for the Council, demonstrated that I had unintentionally become more focused on the perspectives of some occupants. The recognition of the influence my field position had on my interpretation and representation of the data allowed me to moderate my representations and help the team produce a more comprehensive account of the full range of resident experiences. This demonstrates that emotional reflexivity can help the researcher aspire to the benchmark of objectivity as a guiding principle for social researchers. It also demonstrates how qualitative and quantitative researchers from different disciplines can work together collectively to reflect more effectively and to produce a more inclusive account of the research field.

4.3 In conclusion, emotional reflexivity can therefore provide a means for researchers to negotiate the pitfalls of discussing emotions and the reflexive turn and demonstrates how emotions can evolve during the research process. In doing so, emotional reflexivity can help to trace the researcher's path through the research field and reveal the influence this can have on the interpretation and representation of data. This enhances the validity of the findings and, therefore should be seen as a methodological resource. validity of the findings and, therefore should be seen as a methodological resource. This study also indicates that: participants also engage in emotional reflexivity when recounting their stories which may have implications for participant retention in longitudinal studies; research diaries can provide a useful vehicle for recording the emotional content of the interactions between the researcher and the researched that may not be immediately evident in interview transcripts; and that negative emotions may have a more powerful influence on our field positions and interpretations than positive emotions. In conclusion, it seems safe to say that the complex nature of emotions and their multifarious effects on the researchers, the researched and wider field relations require continuing examination and reflection.

\section{Notes}

1 This participant had a disability that affected his mobility.

\section{References}

BAILEY, K (2008) Methods of Social Research, New York: The Free Press.

BARBALET, J (2002) Introduction: why emotions are crucial in Barbalet J (ed.)Emotions and Sociology, Blackwell: Oxford, p. 1-9. [doi:10.1111/j.1467-954x.2002.tb03588.x]

BECKER, H S (1967) Whose side are we on? Social Problems, 14 (3): p. 239-247.

BELLAS, M L (1999) Emotional labour in academia: the case of professors,Annals of the American Academy of 
BLACKMAN, S (2007) Hidden ethnography: crossing emotional borders in qualitative accounts of young people's lives, Sociology, 41 (4): p. 699-716.

BOURDIEU, P and Wacquant, L. (2007) An Invitation to Reflexive Sociology, Chicago: Polity Press.

BREWER, J (2000) Ethnography, Buckingham: The Open University Press.

BROOM, A Cheshire, L. and Emmison, M. (2009). Qualitative researchers' understandings of their practice and the implications for data archiving and sharing, Sociology, 43 (6): p. 1163-1181.

[doi:10.1177/0038038509345704]

BURKITT, I (2012) Emotional reflexivity: feeling, emotion and imagination in reflexive dialogues,Sociology, 46 (3): p. 458-472.

CANTÓ-MILÁ, N (2016) Linking Emotions: Emotions as the invisible threads that bind people together, Sociological Research Online, 21 (1), 10, available via http://www.socresonline.org.uk/21/1/10.htm.

CHRISTIANS C G (2011) Ethics and politics in qualitative research in Denzin NK and Lincoln (eds.)The Sage Handbook of Qualitative research, Sage: London, p. 61-80.

CLARK, T (2008) "'We're over-researched here!": Exploring accounts of research fatigue within qualitative research engagements', Sociology 42 (5): p. 953-70. [doi:10.1177/0038038508094573]

COFFEY, A (2002) Ethnography and self: reflections and representations in May T (ed)Qualitative Research in Action, London: Sage, p. 313-331.

COFFEY, A (1999) The Ethnographic Self, London: Sage. [doi:10.4135/9780857020048]

CUNLIFFE A L (2003) Reflexive inquiry in organizational research: Questions and possibilities, Human Relations, Vol. 56(8), p. 983-1003.

DELAMONT S (2016) Time to kill the witch? Reflections on power relationships when leaving the field in Ward, M.R.M (Ed.) Gender Identity and Research Relationships, Studies in Qualitative Methodology, Vol 14. Bingley; Emerald, p. 3-20.

DICKSON-SWIFT, V, James, E L, Kippen, S. and Liamputtong, P (2009) Researching sensitive topics: qualitative research as emotion work, Qualitative Research, 9 (1): p. 61-79.

FINCH, J (1984). It's great to have someone to talk to: The ethics and politics of interviewing women in Bell C \& Roberts H (Eds.), Social Researching: Politics, Problems, Practice, London: Routledge \& Kegan Paul. p. 70-87. FINLAY, L (2002) Negotiating the swamp: the opportunity and challenge of reflexivity in research practice, Qualitative Research, 2 (2): p. 209-230.

FLAM, H and Kleres J (2016) Inequality and prejudice. German social scientist as producers of feeling rules, Sociological Research Online, 21 (1) 13. Available at http://www.socresonline.org.uk/21/1/13.html.

GOLEMAN, D (1996) Emotional Intelligence: Why it can matter more than IQ London: Bloomsbury.

GOODRUM, S. \& Key, J L (2007) Reflections on two studies of emotionally sensitive topics: bereavement from murder and abortion, International Journal of Social Research Methodology, 10 (4): p. 249-258.

GOULDNER, A (1968) The sociologist as partisan, American Sociologist, May: p. 103-116.

GOULDNER, A (1962) Anti-minotaur: the myth of value-free sociology, Social Problems 9 (3): p. 199-213.

GRAY, B (2008) Putting emotion and reflexivity to work in researching migration,Sociology, 42 (5): p. 935-952. [doi:10.1177/0038038508094571]

HAMMERSLEY, M (2000) Taking Sides in Social Research: Essays on Partisanship and Bias London: Routledge.

HAMMERSLEY, M \& Atkinson, P (1995) Ethnography, London: Routledge.

HAMMERSLEY, M \& Gomm, R (1997) Bias in social research,Sociological Research Online, 2 (1), Available at: 
HARTSOCK, N (1983) The feminist standpoint in Harding S and Hintikka MB (eds.)Discovering Reality: Feminist Perspectives on Epistemology, Metaphysics, Methodology and Philosophy of Science, Dordrecht: Reidel.

HENRY, R (2012) Gifts of grief: performative ethnography and the revelatory potential of emotion, Qualitative Research, 12 (5): p. 528-539

HOCHSCHILD, A R (1985) The Managed Heart: Commercialisation of Human Feeling, Berkeley and London: University of California Press.

HOLLAND, J (2007) Emotions and research, International Journal of Social Research Methodology, 10 (3): p. 195-209.

HOLMES, M (2010) The emotionalization of reflexivity, Sociology, 44 (1): p. 139-154. [doi:10.1177/0038038509351616]

HOMFRAY M (2008) Standpoint, objectivity and social construction: reflections from the study of gay and lesbian communities, Sociological Research Online, 13 (1) 7. Available at http://www.socresonline.org.uk/13/1/7.html.

HUBBARD ,G, Backett-Milburn, K and Kemmer, D (2001) Working with emotion: issues for the researcher in fieldwork and teamwork, International Journal of Social Research Methodology, 4 (2): p. 119-137. [doi:10.1080/13645570116992]

KLEINMAN, S (2002) Emotions, fieldwork and professional lives in May T (ed)Qualitative Research in Action, London: Sage, p. 375-394.

KLEINMAN, S and Copp, MA (1993) Emotions and Fieldwork, Thousand Oaks, CA: Sage. [doi:10.4135/9781412984041]

LUMSDEN, K (2012) 'You are what you research': researcher partisanship and the sociology of the 'underdog', Qualitative Research 13 (3): p. 3-18.

LUMSDEN, K (2009) 'Don't Ask a Woman to Do Another Woman's Job': gendered interactions and the emotional ethnographer', Sociology, 43 (3): p. 497-513. [doi:10.1177/0038038509103205]

MASON, J (2002) Qualitative Researching, London: Sage.

PETRAY, T L (2012) A walk in the park: political emotions and ethnographic vacillation in activist research, Qualitative Research, 12 (5): p. 554-564.[doi:10.1177/1468794112446048]

PILNICK, A (2013) Sociology without frontiers? On the pleasures and perils of interdisciplinary research, Sociological Research Online, 18 (3) 9. Available at http://www.socresonline.org.uk/18/3/9.html.

ROMOCEA, O (2014) Ethics and emotions: a migrant researcher doing research among Romanian migrants, Sociological Research Online, 19 (4), 16. Available at:http://www.socresonline.org.uk/19/4/16.html. [doi:10.5153/sro.3489]

SEAL, L (2012) Emotions and allegiance in researching four mid-20h-century cases of women accused of murder, Qualitative Research, 12 (6): p. 686-701.

SEEBACH, S and Nùnez-Mosteo F (2016) Is romantic love a linking emotion?,Sociological Research Online, 21 (1), 14. Available at http://www.socresonline.org.uk/21/1/14.html. [doi:10.5153/sro.3828]

SHILLING, C (2003) The Body and Social Theory, London: Sage.

TEWKSBURY, R (2009) Qualitative versus quantitative methods: understanding why qualitative methods are superior for criminology and criminal justice, Journal of Theoretical and Philosophical Criminology, 1 (1): p. 38-58.

TRIGGER D, Forsley, M and Meurk, C (2012) Revelatory moments in field work, Qualitative Research, 12 (5): p. 513-527. 
WARD, MRM (2016) The importance of gender reflexivity in the research process, in Ward, M.R.M (Ed.) Gender Identity and Research Relationships, Studies in Qualitative Methodology, Vol 14. Bingley; Emerald, ixxvi. 